\title{
Perceived Stress and Depressive Symptoms in Undergraduate Students: The Effect of Emotional Eating
}

\author{
Maya Amestoy ${ }^{1}$ and Alexandra J. Fiocco ${ }^{1 \#}$ \\ ${ }^{1}$ Ryerson University, Toronto, Ontario, CA \\ \#Advisor
}

$\underline{\text { ABSTRACT }}$

With a rise in the prevalence of depression among undergraduate students, it is important to identify potential antecedents and modifiable factors in illness development. One of the most well studied etiological predictors of depression among youth and among young adults is the experience of real or perceived stress. However, research further suggests that the impact of stress on health outcomes may largely depend on the coping strategies employed. Emotional eating is an emotion-focused coping strategy that may be used to minimize negative affect stemming from perceived stress. The objective of this cross-sectional study was to investigate the moderating role of emotional eating in the relationship between perceived stress and depressive symptoms among undergraduate students. A total of 100 undergraduate students (mean age $=20.2$ years, $83 \%$ female) completed questionnaires that tapped into perceived stress, emotional eating behaviour, and depressive symptoms. Moderation analyses revealed a significant moderation effect $(b=.016, t(91)=2.728, p=.008)$. Simple slopes showed that the magnitude of the association between perceived stress and depressive symptoms increased from low $(b=.092)$ to moderate $(b=.147)$ to high $(b=.201)$ emotional eating tendencies. Findings suggest that perceived stress and emotional eating may have a synergist association with depressive symptoms among undergraduate students.

\section{Introduction}

In recent years, the prevalence of depression among undergraduate students has risen, surpassing the prevalence of depression in the general population (Ceyhan et al., 2009; Ibrahim et al., 2013). In a systematic review of 24 studies examining the prevalence rate of depression among post-secondary students, it was found that the prevalence of depression ranged from $10 \%$ to $85 \%$, with a weighted mean prevalence of $30.6 \%$ (Ibrahim et al., 2013). As depression may run a chronic course and significantly impact an individual's performance and quality of life, it is important to investigate factors that contribute to the risk of disease development. Exposure to real or perceived stress is one etiological factor that has been shown to contribute to the development of depression (Yang et al., 2015).

Transitioning to university or college is often a challenging life event that can result in elevated perceptions of stress, which may increase the risk of depression. During this time, students may feel overwhelmed by the demands of post-secondary course workload, impending deadlines, the pressure to succeed, and living independently (Dyson \& Renk, 2006). Moreover, being a non-traditional student (i.e., mature student, working part- or full-time, and/or having dependents) may encompass an additional subset of demands involving work and financial obligations, and caregiving responsibilities (Spellman, 2007). Together, the collection of demands experienced by post-secondary students may lead to heightened perceived stress, which in turn may increase negative affect (Feldman et al., 1999), and the presentation of depressive symptoms (O'Hara et al., 2014). In a 2019 national survey of 67,972 post-secondary students (American College of Health Association (ACHA), 2019), 13.4\% of respondents reported tremendous stress and $45.3 \%$ reported more than average stress in the last 12 months. Further, $87.4 \%$ felt overwhelmed with the tasks 
they had to accomplish, $70.8 \%$ felt very sad, $55.9 \%$ reported feeling hopeless, and $45 \%$ felt so depressed that it was difficult to function. Approximately $20 \%$ of post-secondary students were being treated for depression (ACHA, 2019). Together, these statistics suggest that the perception of stress may vary between students, despite being exposed to similar environmental challenges (Monroe et al., 2019).

According to the Transactional Model of Stress, the perception of stress stems from an evaluative process in which the situational demands exceed available resources to manage those demands (Lazarus \& Folkman, 1984). Coping refers to the behavioral and cognitive strategies engaged in to manage situations that are appraised as threatening or stressful (Skinner \& Wellborn, 1994). While many coping strategies exist, these strategies are often labelled as problem-focused or emotion-focused coping styles. Problem-focused coping involves managing the stressor or threat; whereas emotion-focused coping involves managing the distress that stems from the stressor or threat (Folkman \& Lazarus, 1980). The utility of problem-focused strategies relative to emotion-focused strategies largely depends on the extent to which the individual has control of the stressor at hand. Furthermore, while some strategies may be adaptive in the short run, long term use may be maladaptive and lead to negative outcomes (McNamara, 2000). Indeed, previous research has found passive emotion-focused coping strategies may become maladaptive overtime, and have been associated with depressive symptoms in post-secondary students (Chou et al., 2011).

Emotional eating, defined as a tendency to eat in response to negative emotions, is a common emotion-focused coping strategy (Spoor et al., 2007). Individuals who engage in emotional eating do so to eliminate feelings of distress, irrespective of internal sensations of hunger and satiety (Conner et al., 1999). Affect-related models such as the escape from self-awareness model, suggests that emotional eating in response to negative affect may suppress feelings of negative emotions by narrowing focused attention on food intake (Heatherton \& Baumeister, 1991; Wallis \& Hetherington, 2004). The foods most often consumed to alleviate feelings of distress are highly palatable, energydense, snack-type foods that are characterized by high levels of sugar, sodium, and fat content (Dallman 2010; Kandiah et al., 2006; Zellner et al., 2006). In a study examining the influence of acute stress on eating behavior in 68 men and women, it was found that stressed emotional eaters consumed more sweet, high-fat, and energy-dense foods relative to non-stressed participants and stressed non-emotional eaters (Oliver et al., 2000). Overall, palatable foods are reported to produce a gratifying feeling, or feelings of nostalgia, that may assist in minimizing the discomfort of perceived stress (Dallman, 2010; Polivy et al., 1994).

Undergraduate students who report high levels of stress are more likely to report increased consumption of cookies, cake, and chocolate (Oliver \& Wardle, 1999), and display a higher frequency of fast-food intake (Almogbel et al., 2019). Consequently, the term "Freshman 15" has emerged as a result of this trend to characterize this notion of ample weight gain during post-secondary years (Zagorsky \& Smith, 2011). Although emotional eating may provide temporary comfort and distraction, frequent utilization of this strategy may be maladaptive in the long run (Rutledge \& Linden, 1998), and may exacerbate the impact of stress on psychological and physical health outcomes (Lazarus \& Folkman, 1984).

The objective of the current study was to investigate the moderating role of emotional eating in the relationship between perceived stress and depressive symptoms among undergraduate students. It was hypothesized that engaging in emotional eating would moderate the association between perceived stress and depression, such that greater engagement in emotional eating tendencies would exacerbate the association between perceived stress and self-report depressive symptoms. Understanding the potential negative impact of emotional eating in response to stress among undergraduate populations is important for the development of education tools and the promotion of mental health strategies across post-secondary institutions.

\section{Methods}

Participants 
A total of 100 undergraduate students enrolled in an Introductory Psychology course were recruited as part of a larger study which examined the effect of acute stress on eating behavior in a laboratory setting. Prospective participants who self-reported a diagnosed eating disorder, personality disorder, bipolar disorder, or autism spectrum disorder were excluded from the study.

Measures

\section{Sociodemographic and Health-related Information}

Participants completed a sociodemographic and health questionnaire that collected data on age, biological sex, socioeconomic status, program and year of study, and health-related characteristics including dietary pattern adherence (e.g., vegetarian, pescatarian, etc.), sleep, weight, and height, which were used to calculate body mass index (BMI). See Appendix A.

\section{Perceived Stress}

The 10-item Perceived Stress Scale (PSS-10; Cohen et al., 1983) is a Likert-type scale that measures the degree to which situations over the past month have been appraised as stressful (Cohen et al., 1983). The total score ranges from 0 to 40, with higher scores indicating greater perceived levels of stress. The PSS-10 has demonstrated good internal consistency in a sample of undergraduate students $(\alpha=.85$; Cohen et al.,1983). See Appendix B.

\section{Depression}

The 21-item Depression, Anxiety, and Stress Scale (DASS-21; Lovibond \& Lovibond, 1995) is a Likert-type scale that measures symptoms of depression, anxiety, and stress within the previous week. The total score on the DASS-21 ranges from 0 to 120 , with higher scores indicating greater combined symptoms of depression, anxiety, and stress (Osman et al., 2012). Only the depression subscale was used for this study, with scores ranging from 0 to 42, with higher scores indicating greater depressive symptoms. The DASS-21 has been validated in a sample of undergraduate students, with a Cronbach's $\alpha=.85$ for the depression scale (Osman et al., 2012). See Appendix C.

\section{Emotional Eating}

An Emotional Eating Behavior Questionnaire (EEQ) is a questionnaire designed by Wildwood Family Clinic for healthy eating coaching ("Wildwood Family Clinic", n.d.). The EEQ was administered to participants to identify emotional eating tendencies and relationship with food. The questionnaire consists of 18 statements that include examples of the most common types of emotional eating: depressed eating, anxiety/ stress eating, angry eating, bored eating, lonely eating, and happy eating. The scores on the EEQ range from 0 to 18 , with higher scores indicating greater emotional eating tendencies. See Appendix D.

\section{Procedure}

Participants who met inclusion/exclusion criteria visited the research laboratory between 8 a.m. to 8 p.m. Following the provision of consent, participants were randomized to a stress-induction task or a non-stressful control condition and were asked to report their affect and desire to eat at pre-determined measurement points. All participants completed a set of questionnaires to ensure equivalence between groups on general perceived stress, emotional eating behavior, and depressive symptoms. This study was approved by the Ryerson University Research Ethics Board (REB 2019-309). 


\section{Statistical Analyses}

The current study is a secondary analysis of the baseline data collected within the entire sample, with particular focus on general perceived stress, emotional eating behavior, and depressive symptoms. Data were checked for assumptions of linear regression. Depression scores did not meet the assumptions of normality and therefore square root transformation (SQRT) was performed to fit the normal distribution. Scores on the PSS-10 and the EEQ met all assumptions. A priori covariates included sex and body mass index (BMI) due to their potential associations with depression (Eid et al., 2019; Weinberger et al., 2018), and perceived stress (Harding et al., 2014; Xu et al., 2016).

Pearson correlations were conducted to assess zero-order correlations between all variables of interest and covariates. To test for the moderating effect of emotional eating in the relationship between perceived stress and depression, SPSS PROCESS Macro (Model 1, Hayes, 2017) was used with bootstrapping (5000 samples). SQRT Depression score was entered as the dependent variable (Y), PSS-10 was entered as the independent variable (X), EEQ was entered as the moderating variable (W), and sex and BMI were entered as model covariates (CV1, CV2). All continuous variables were mean-centered. Simple slopes derived from the model reflect conditional effects of the independent variable on the dependent variable, at mean level of the moderator (i.e., average emotional eating behavior), one standard deviation (SD) above the mean (i.e., high level emotional eating behavior), and one SD below the mean (i.e., low level emotional eating behavior). All statistical analyses were conducted using IBM SPSS Statistics v21, and two-tailed $p$-values of .05 were used to detect statistical significance for all analyses.

\section{Results}

\section{Participant Characteristics}

As displayed in Table 1, 83\% of the sample was female, with a mean age of $20.20 \pm 4.77$ years. The sample was ethnically diverse, with $43 \%$ Asian and 31\% Caucasian/ European. A majority of the participants were in their first year of study (61\%) and $55 \%$ of participants were employed while attending university. The mean PSS-10 score was 20.4 (6.32), suggesting that participants on average perceived a high level of stress over the past month. The mean DASS-21 depression subscale score was 9.46 (9.16), suggesting a moderate level of depressive symptoms over the past week. The mean EEQ was 7.75 (3.34), suggesting moderate levels of emotional eating.

Table 1. Participant Demographic and Health-Related Characteristics

\begin{tabular}{ll}
\hline Study Variable & $\%$ or Mean \pm SD (range) \\
\hline Sex (\% female) & $83 \%$ \\
Age & $20.2 \pm 4.77(17-51)$ \\
Ethnicity (\%) & $31 \%$ \\
$\quad$ Caucasian/ European & $43 \%$ \\
$\quad$ Asian & $9 \%$ \\
$\quad$ Middle Eastern & $17 \%$ \\
$\quad$ Other & \\
Perceived Socioeconomic Status (\%) & $9 \%$ \\
$\quad$ Low
\end{tabular}




\begin{tabular}{|c|c|}
\hline Middle-High & $91 \%$ \\
\hline \multicolumn{2}{|l|}{ Program of Study (\%) } \\
\hline Psychology & $13 \%$ \\
\hline Biology/ Biomedical Sciences & $26 \%$ \\
\hline Early Childhood Studies/ Child and Youth Care & $14 \%$ \\
\hline Nursing & $11 \%$ \\
\hline Other & $36 \%$ \\
\hline \multicolumn{2}{|l|}{ Year of Study (\%) } \\
\hline First year undergraduate & $61 \%$ \\
\hline Second year undergraduate & $8 \%$ \\
\hline Third year undergraduate & $18 \%$ \\
\hline Fourth year undergraduate & $8 \%$ \\
\hline Other & $5 \%$ \\
\hline \multicolumn{2}{|l|}{ Diet $(\%)$} \\
\hline Western diet & $48 \%$ \\
\hline Mediterranean/ Prudent diet & $31 \%$ \\
\hline Other & $20 \%$ \\
\hline \multicolumn{2}{|l|}{ Employment } \\
\hline Not employed while attending school & $50 \%$ \\
\hline Part-time & $43 \%$ \\
\hline Full-time & $7 \%$ \\
\hline Average Hours of Sleep in the Past 4-weeks & $6.49 \pm 1.22(3-10)$ \\
\hline BMI & $23.32 \pm 4.68(15.94-39.16)$ \\
\hline PSS-10 & $20.4 \pm 6.32(4-36)$ \\
\hline DASS-21 Depression Subscale (raw) & $9.46 \pm 9.16(0-38)$ \\
\hline DASS-21 Depression Subscale (SQRT) & $2.59 \pm 1.67(0-6.16)$ \\
\hline EEQ & $7.75 \pm 3.34(0-14)$ \\
\hline
\end{tabular}

Notes: Percentage (\%) reflects proportion of respondents; $\mathrm{SD}=$ Standard deviation; BMI = Body mass index; PSS$10=$ Perceived Stress Scale; DASS-21 = Depression, Anxiety, and Stress Scale; SQRT = Square-root transformed; $\mathrm{EEQ}=$ Emotional Eating Questionnaire. 


\section{Emotional Eating as a Moderator in the Relationship Between Perceived Stress and Depression}

Pearson correlation revealed significant zero-order correlations between scores on the PSS-10 and SQRT DASS-21 depression $(r=.501, p<.001)$, scores on the PSS-10 and EEQ $(r=.241, p=.016)$, and scores on the EEQ and SQRT DASS-21 depression $(r=.233, p=.020)$.

Controlling for sex and BMI, the moderation model was statistically significant $\left(F(5,91)=9.472, p<.001, R^{2}=\right.$ .342). Analysis of main effects showed that scores on the PSS-10 significantly associated with SQRT transformed scores on the DASS-21 depression scale, $(b=.147, t(91)=6.016, p<.001)$, suggesting that higher perceived stress associated with higher depressive symptom scores. EEQ did not associate with SQRT transformed scores on the DASS-21-Depression scale $(b=.039, t(91)=.857, p=.393)$. A significant interaction effect between PSS-10 and EEQ was found $(b=.016, t(91)=2.728, p=.008)$. Further, addition of the interaction term significantly improved the overall model $\left(F(1,91)=7.443, p=.008, R^{2}\right.$ change $\left.=.054\right)$.

Figure 1 displays the conditional effects of PSS-10 on SQRT transformed scores on the DASS-21 depression scale, at three levels of EEQ: one SD below the mean (value = -.312), mean EEQ (value $=0$ ), and one SD above the mean (value $=3.312$ ). PSS-10 associated with depression at the lower level of EEQ $(b=.092, t(91)=3.344, p=.001)$, mean level of EEQ $(b=.147, t(91)=6.016, p<.001)$ and higher level of EEQ $(b=.201, t(91)=5.769, p<.001)$. As displayed in Figure 1, although PSS-10 associated with depression at different levels of EEQ, the estimated slopes strengthened from lower to higher level of EEQ $(b=.092<.147<.201)$. Johnson-Neyman procedure suggested the significance region to be at the EEQ value of -4.895 (where $b=.067, t(91)=1.986, p=.05$ ).

Figure 1. Simple slopes reflecting the association between perceived stress and depression at three levels of emotional eating behaviour.

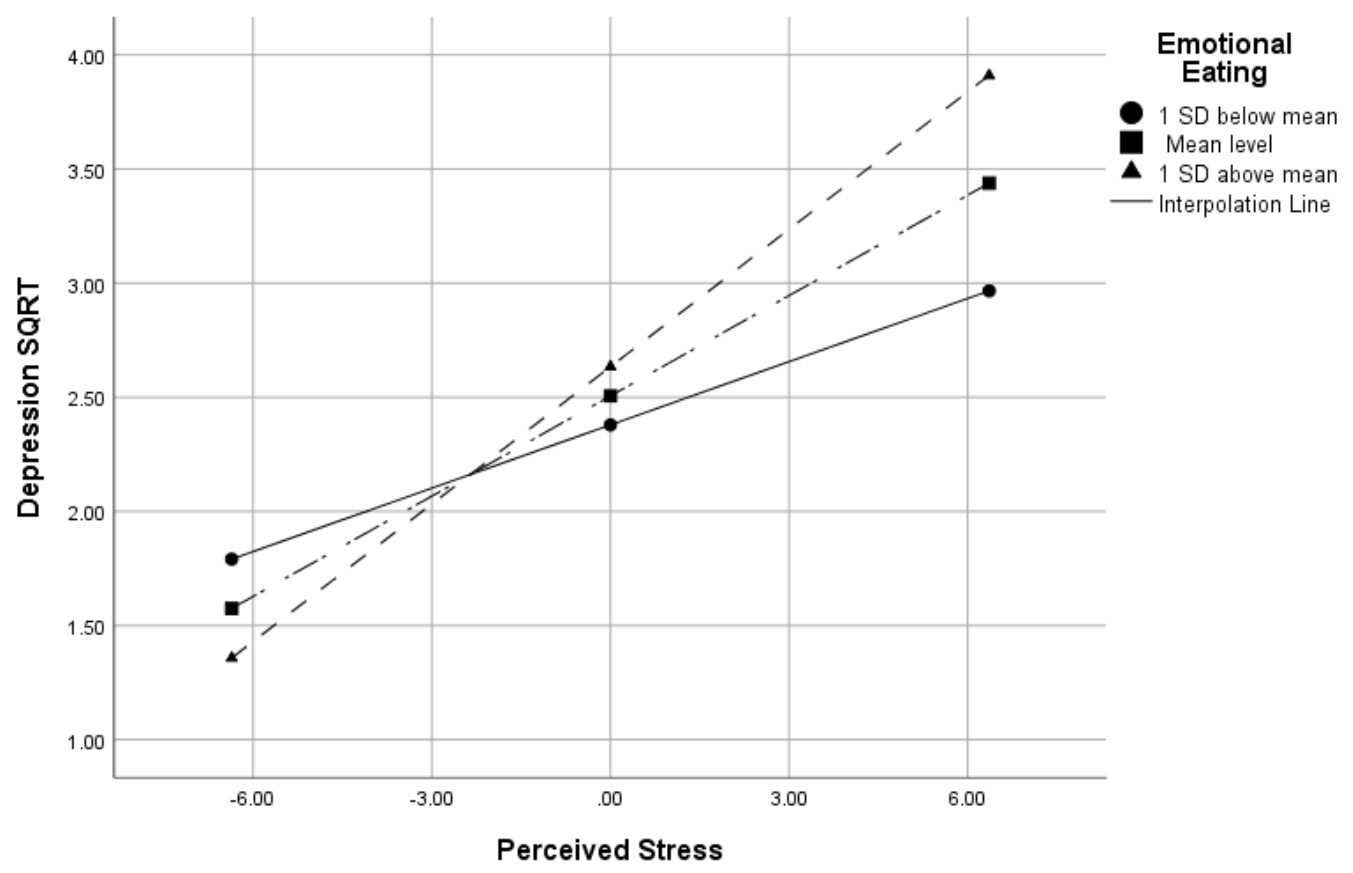




\section{Discussion}

Over the last decade, mental health among undergraduate students has become an important point of focus due to the rise in stress-related health ailments, including the experience of depression (Ibrahim et al., 2013). The current study examined the moderating role of emotional eating tendencies in the relationship between perceived stress and depressive symptoms. The proposed hypothesis was supported such that the tendencies to engage in emotional eating exacerbated the relationship between perceived stress and depressive symptoms among undergraduate students. More specifically, although a robust association between perceived stress over the last month and depressive symptoms over the last week was observed, the magnitude of the association increased in a step-wise fashion from low emotional eating to high emotional eating behavior.

Individuals who engage in emotional eating as a coping strategy have a tendency to consume palatable snacktype foods in response to stress (Macht \& Simons, 2000; O'Connor et al., 2008; Oliver et al., 2000). Despite the temporary benefits associated with emotional eating as a coping strategy to mitigate negative affect, long-term use of emotional eating in response to daily hassles may impose negative health consequences. In the context of the current study, perceived stress couples with emotional eating may have a synergistic effect on depressive symptoms.

The synergistic effect of perceived stress and emotional eating on depression may stem from shared underlying biological mechanisms. In recent years, research has revealed peripheral inflammation as a potential antecedent in the development of depression (Lee \& Giuliani, 2019), evidenced by increased low-grade inflammation among patients with depression relative to healthy controls (Osimo et al., 2019), and prospective longitudinal studies associating elevated inflammatory markers with subsequent development of depressive symptoms (Valkanova et al., 2013). In addition to the robust association between activation of stress-sensitive systems and increased peripheral circulation of inflammatory cytokines (Marsland et al., 2017), high fat and sugar intake may further enhance systemic inflammation (Dickinson et al., 2008; Gregersen et al., 2012; Lundman et al., 2007). Accordingly, undergraduate students who perceive high levels of stress and display a tendency to engage in emotional eating of palatable foods may be at increased risk of presenting with depressive symptoms due to low-grade systemic inflammation (Liu et al., 2007).

Interpretations of the study findings are made in light of a few notable study limitations. The cross-cultural design of the current study prevents causal inferences pertaining to the association between perceived stress and depressive symptoms, and the moderating role of emotional eating. The bidirectional relationship between the test variables is important to acknowledge. For instance, previous research suggests that depression may lead to heightened levels of perceived stress (Hammen, 2005) and increased consumption of palatable foods (van Strien et al., 2016). Although the questionnaires tapping into perceived stress and depressive symptoms reflect different time periods (past month for perceived stress and past week for perceived depression), it is unknown whether depressive symptoms preceded reports of generalized stress. It is also important to highlight that the current study did not assess clinical depression, but rather measured the presentation of depressive symptoms.

Future research is needed to replicate and expand on the current findings in a larger and more diverse population to assess the consistency of these findings. Longitudinal studies are needed to examine the causality and evaluate the long-term effects of emotional eating on the relationship between stress, depression, and other stress-related ailments including metabolic disorder among young adults.

\section{Conclusion}

This research contributes to the growing body of literature examining the relationship between perceived stress and mental health among undergraduate students, a segment of the population that has shown a rise in mental health disorders, including depression. The cultivation of effective coping strategies may enable undergraduate students to better manage the challenges of university and college years and minimize the emergence of depressive symptoms 
and other mental health ailments. The findings are important as they highlight the potential negative influence of stress-reactive emotional eating tendencies on depressive symptoms. Moreover, this research underscores the importance of developing multidisciplinary lifestyle-based prevention strategies that include healthy eating interventions across post-secondary institutions.

\section{Acknowledgements}

The authors would like to thank our participants.

\section{References}

Almogbel, E., Aladhadh, A. M., Almotyri, B. H., Alhumaid, A. F., \& Rasheed, N. (2019). Stress Associated Alterations in Dietary Behaviours of Undergraduate Students of Qassim University, Saudi Arabia. Open access Macedonian journal of medical sciences, 7(13), 2182-2188. https://doi.org/10.3889/oamjms.2019.571

American College Health Association (2019). American College Health. Association-National College Health Assessment II: Reference Group Executive Summary Spring 2019. Silver Spring, MD: American College Health Association.

Ceyhan, A., Ceyhan, E., Kurty, Y. (2009). Investigation of university students' depression. Eurasian Journal of Educational Research, 36, 75-90.

Chou, P., Chao, Y. Y., Yang, H., Yeh, G., \& Lee, T. S. (2011). Relationships between stress, coping and depressive symptoms among overseas university preparatory chinese students: A cross-sectional study. BMC Public Health, 11(1), 352-352. https://doi.org/10.1186/1471-2458-11-352

Cohen, S., Kamarck, T., \& Mermelstein, R. (1983). A global measure of perceived stress. Journal of Health and Social Behavior, 24(4), 385-396. https://doi.org/10.2307/2136404

Conner, M., Fitter, M., \& Fletcher, W. (1999). Stress and snacking: A diary study of daily hassles and between-meal snacking. Psychology \& Health, 14(1), 51-63. https://doi.org/10.1080/08870449908407313

Dallman, M. F. (2010). Stress-induced obesity and the emotional nervous system. Trends in Endocrinology \& Metabolism, 21(3), 159-165. https://doi.org/10.1016/j.tem.2009.10.004

Dickinson, S., Hancock, D. P., Petocz, P., Ceriello, A., \& Brand-Miller, J. (2008). High-glycemic index carbohydrate increases nuclear factor-kappaB activation in mononuclear cells of young, lean healthy subjects. American Journal of Clinical Nutrition, 87(5), 1188-1193. https://doi.org/10.1093/ajcn/87.5.1188

Dyson, R., \& Renk, K. (2006). Freshmen adaptation to university life: depressive symptoms, stress, and coping. Journal of Clinical Psychology, 62(10), 1231-1244. https://doi.org/ 10.1002/jclp.20295

Eid, R. S., Gobinath, A. R., \& Galea, L. (2019). Sex differences in depression: Insights from clinical and preclinical studies. Progress in neurobiology, 176, 86-102. https://doi.org/10.1016/j.pneurobio.2019.01.006

Feldman, P. J., Cohen, S., Lepore, S. J., Matthews, K. A., Kamarck, T. W., \& Marsland, A. L. (1999). Negative emotions and acute physiological responses to stress. Annals of behavioral medicine : a publication of the 
Society of Behavioral Medicine, 21(3), 216-226. https://doi.org/10.1007/BF02884836

Folkman, S., \& Lazarus, R. S. (1980). An analysis of coping in a middle-aged community sample. Journal of Health and Social Behavior, 21(3), 219-239. https://doi.org/10.2307/2136617

Gregersen, S., Samocha-Bonet, D., Heilbronn, L. K., Campbell, L. V. (2012). Inflammatory and oxidative stress responses to high-carbohydrate and high-fat meals in healthy humans. Journal of Nutrition and Metabolism, 238056, 8 pages. https://doi.org/10.1155/2012/238056

Hammen C. (2005). Stress and depression. Annual review of clinical psychology, 1, 293-319. https://doi.org/10.1146/annurev.clinpsy.1.102803.143938

Harding, J. L., Backholer, K., Williams, E. D., Peeters, A., Cameron, A. J., Hare, M. J., Shaw, J. E., \& Magliano, D. J. (2014). Psychosocial stress is positively associated with body mass index gain over 5 years: evidence from the longitudinal AusDiab study. Obesity, 22(1), 277-286. https://doi.org/10.1002/oby.20423

Hayes, A. F. (2017). Introduction to mediation, moderation, and conditional process analyses: A regression-based approach. New York, NY: The Guilford Press.

Heatherton, T. F., \& Baumeister, R. F. (1991). Binge eating as escape from self-awareness. Psychological bulletin, 110(1), 86-108. https://doi.org/10.1037/0033-2909.110.1.86

Ibrahim, A. K., Kelly, S. J., Adams, C. E., \& Glazebrook, C. (2013). A systematic review of studies of depression prevalence in university students. Journal of Psychiatric Research, 47(3), 391-400. https://doi.org/10.1016/i.jpsychires.2012.11.015

Kandiah, J., Yake, M., Jones, J. and Meyer, M. (2006) Stress Influences Appetite and Comfort Food Preferences in College Women. Nutrition Research, 26, 118-123. https://doi.org/10.1016/j.nutres.2005.11.010

Lazarus, R. S., \& Folkman, S. (1984). Stress, appraisal, and coping Springer Pub. Co

Lee, C. H., \& Giuliani, F. (2019). The Role of Inflammation in Depression and Fatigue. Frontiers in immunology, 10, 1696. https://doi.org/10.3389/fimmu.2019.01696

Liu, C., Xie, B., Chou, C., Koprowski, C., Zhou, D., Palmer, P., . . Anderson Johnson, C. (2007). Perceived stress, depression and food consumption frequency in the college students of china seven cities. Physiology \& Behavior, 92(4), 748-754. https://doi.org/10.1016/j.physbeh.2007.05.068

Lovibond, S. H., \& Lovibond, P. F. (1995). The structure of negative emotional states: Comparison of the depression anxiety stress scales (DASS) with the beck depression and anxiety inventories. Behaviour Research and Therapy, 33(3), 335-343. https://doi.org/10.1016/0005-7967(94)00075-U

Lundman, P., Boquist, S., Samnegard, A., Bennermo, M., Held, C., Ericsson, C-G., Silveira, A., Hamsten, A., Tornvall, P. (2007). A high-fat meal is accompanied by increased plasma interleukin-6 concentrations. Nutrition, Metabolism and Cardiovascular Disease, 17(3), 195-202. 
Macht, M. \& Simons, G. (2000). Emotions and eating in everyday life. Appetite, 35(1), 65-71. https://doiorg.ezproxy.lib.ryerson.ca/10.1006/appe.2000.0325

Marsland, A. L., Walsh, C., Lockwood, K., \& John-Henderson, N. A. (2017). The effects of acute psychological stress on circulating and stimulated inflammatory markers: A systematic review and meta-analysis. Brain, behavior, and immunity, 64, 208-219. https://doi.org/10.1016/j.bbi.2017.01.011

McNamara, S. (2000). Stress in young people: Whats new and what can we do? New York: Continuum.

Monroe, S. M., Anderson, S. F., \& Harkness, K. L. (2019). Life stress and major depression: The mysteries of recurrences. Psychological Review, 126(6), 791-816. https://doi.org/10.1037/rev0000157

O'Connor, D. B., Jones, F., Conner, M., McMillan, B., \& Ferguson, E. (2008). Effects of daily hassles and eating style on eating behavior. Health psychology: official journal of the Division of Health Psychology, American Psychological Association, 27(1S), S20-S31. https://doi.org/10.1037/0278-6133.27.1.S20

O'Hara, R. E., Armeli, S., Boynton, M. H., \& Tennen, H. (2014). Emotional stress-reactivity and positive affect among college students: the role of depression history. Emotion, 14(1), 193-202.

https://doi.org/10.1037/a0034217

Oliver, G., \& Wardle, J. (1999). Perceived Effects of Stress on Food Choice. Physiology \& Behaviour, 66(3), 511 515. https://doi.org/10.1016/S0031-9384(98)00322-9

Oliver, G., Wardle, J., \& Gibson, E. L. (2000). Stress and food choice: a laboratory study. Psychosomatic medicine, 62(6), 853-865. https://doi.org/10.1097/00006842-200011000-00016

Osimo, E., Baxter, L., Lewis, G., Jones, P., \& Khandaker, G. (2019). Prevalence of low-grade inflammation in depression: A systematic review and meta-analysis of CRP levels. Psychological Medicine, 49(12), 1958-1970. https://doi.org/10.1017/S0033291719001454

Osman, A., Wong, J. L., Bagge, C. L., Freedenthal, S., Gutierrez, P. M., \& Lozano, G. (2012). The Depression Anxiety Stress Scales-21 (DASS-21): further examination of dimensions, scale reliability, and correlates. Journal of clinical psychology, 68(12), 1322-1338. https://doi.org/10.1002/jclp.21908

Polivy, J., Herman, C. P., \& McFarlane, T. (1994). Effects of anxiety on eating: Does palatability moderate distressinduced overeating in dieters? Journal of Abnormal Psychology, 103(3), 505-510. https://doi.org/10.1037//0021$\underline{843 X} .103 .3 .505$

Rutledge, T., \& Linden, W. (1998). To eat or not to eat: Affective and physiological mechanisms in the StressEating relationship. Journal of Behavioral Medicine, 21(3), 221-240. https://doi.org/10.1023/A:101878401577

Skinner, E. A., \& Wellborn, J. G. (1994). Coping during childhood and adolescence: A motivational perspective. Life-Span Development and Behavior, 12, 91-133.

Spellman, N. (2007). Enrollment and Retention Barriers Adult Students Encounter. The Community College Enterprise, 13, 63-79. 
Spoor, S. T., Bekker, M. H., Van Strien, T., \& van Heck, G. L. (2007). Relations between negative affect, coping, and emotional eating. Appetite, 48(3), 368-376. https://doi.org/10.1016/j.appet.2006.10.005

Tomiyama, A. J., Dallman, M. F., \& Epel, E. S. (2011). Comfort food is comforting to those most stressed: Evidence of the chronic stress response network in high stress women. Psychoneuroendocrinology, 36(10), 1513-1519. https://doi.org/10.1016/j.psyneuen.2011.04.005

Valkanova, V., Ebmeier, K. P., \& Allan, C. L. (2013). CRP, IL-6 and depression: a systematic review and metaanalysis of longitudinal studies. Journal of affective disorders, 150(3), 736-744.

https://doi.org/10.1016/j.jad.2013.06.004

van Strien, T., Konttinen, H., Homberg, J. R., Engels, R. C., \& Winkens, L. H. (2016). Emotional eating as a mediator between depression and weight gain. Appetite, 100, 216-224.

https://doi.org/10.1016/j.appet.2016.02.034

Wallis, D. J., \& Hetherington, M. M. (2004). Stress and eating: the effects of ego-threat and cognitive demand on food intake in restrained and emotional eaters. Appetite, 43(1), 39-46.

https://doi.org/10.1016/j.appet.2004.02.001

Weinberger, A. H., Gbedemah, M., Martinez, A. M., Nash, D., Galea, S., \& Goodwin, R. D. (2018). Trends in depression prevalence in the USA from 2005 to 2015: widening disparities in vulnerable groups. Psychological medicine, 48(8), 1308-1315. https://doi.org/10.1017/S0033291717002781

Xu, X., Bao, H., Strait, K., Spertus, J. A., Lichtman, J. H., D'Onofrio, G., Spatz, E., Bucholz, E. M., Geda, M., Lorenze, N. P., Bueno, H., Beltrame, J. F., \& Krumholz, H. M. (2015). Sex differences in perceived stress and early recovery in young and middle-aged patients with acute myocardial infarction. Circulation, 131(7), 614623. https://doi.org/10.1161/CIRCULATIONAHA.114.012826

Yang, L., Zhao, Y., Wang, Y., Liu, L., Zhang, X., Li, B., \& Cui, R. (2015). The Effects of Psychological Stress on Depression. Current neuropharmacology, 13(4), 494-504. https://doi.org/10.2174/1570159x1304150831150507

Zagorsky, J. L., \& Smith, P. K. (2011). The freshman 15: A critical time for obesity intervention or media myth. Social Science Quarterly, 92(5), 1389-1407. https://doi.org/10.1111/j.1540-6237.2011.00823.x

Zellner, D. A., Loaiza, S., Gonzalez, Z., Pita, J., Morales, J., Pecora, D., \& Wolf, A. (2006). Food selection changes under stress. Physiology \& Behavior, 87(4), 789-793. https://doi.org/10.1016/j.physbeh.2006.01.014 